DE AQUILES A RIOBALDO:

AÇÃO LENDÁRIA NO ESPAÇO MÁGICO

FOM AQUILES TO RIOBALDO:

LEGENDARY ACTION IN THE MAGIC SPACE

Elizabeth Hazin*

RESUMO: Apresentam-se, aqui, breves considerações a respeito da correspondência entre dois universos épicos: o da Ilíada de Homero e o do Grande Sertão: Veredas, de Guimarães Rosa, a partir da observação dos manuscritos do autor e de comentários feitos por Antonio Candido sobre o romance do escritor mineiro.

PALAVRAS-CHAVE: Crítica Genética, Guimarães Rosa, Grande sertão: veredas, épica, Ilíada.

ABSTRACT: We aim to present, here, brief considerations about the correspondence between two epic universes: one from the Iliad, by Homer e other from Grandes Sertões: Veredas, by Guimarães Rosa, departing from the analysis of the commentaries made by Antonio Candido on the Brazilian writer's novel and the author's manuscripts.

KEY WORDS: Genetic criticism, Guimarães Rosa, Grande sertão: veredas, epic, Iliad.

* Pós-doutorado em Literatura Brasileira. Prof. do Programa de Pós-Graduação em Literatura da Universidade de Brasília. Email: ehazin@ig.com.br. 



\section{DE AQUILES A RIOBALDO: AÇÃO LENDÁRIA NO ESPAÇO MÁGICO}

Em 1991, defendi tese de doutoramento sobre o livro Grande sertão: veredas, da autoria de Guimarães Rosa. Não se tratava, entretanto, de mais uma análise do romance, mas sim de uma perquirição de sua escritura na fase do processo de sua elaboração, o que implicava minucioso exame dos manuscritos do autor, para conhecer o que havia de anterior ao texto publicado.

Estudando-se os manuscritos de um autor, é possível não apenas retraçar a gênese de uma dada obra literária, como também descobrir elementos preciosos que ajudem o crítico no desvendamento de significados do texto. No caso do Grande sertão: veredas, tive em mãos - à época da minha tese -, os documentos depositados no arquivo do IEB, Instituto de Estudos Brasileiros (USP), relativos ao romance, bem como as primeira e segunda versões do livro, denominadas pelo próprio autor Primeiro Rascunho e Segundo Rascunho, ambos cedidos a mim, para exame, por D. Aracy M. de Carvalho, viúva do escritor, em 1986. O Primeiro Rascunho, datilografado, apresenta ao longo de suas 356 páginas inúmeras alterações de próprio punho, a lápis preto comum (a grande maioria), a tinta azul ou ainda a lápis de cor, predominantemente vermelho, azul, verde e roxo. A sua alteração mais notável é a inserção de palavras e frases, e é exatamente através desse procedimento que o texto se alonga e se dilata. Por sua vez, o Segundo Rascunho está mais próximo do livro pronto, no que diz respeito à organização. Não apresenta alterações manuscritas e inclui uma folha de rosto, contendo título, subtítulo e nome da editora. Trata-se de cópia obtida, a partir de papel 
carbono, de original entregue à Editora José Olympio, visando à publicação. Foi datilografado em máquina diferente daquela do Primeiro Rascunho (os tipos são outros) e compreende 461 páginas, ou seja, 105 a mais que o Primeiro. Na última, traz manuscrita a seguinte anotação:

(Em 22 de novembro de 1955.

Às $12 \mathrm{hs}, 32$ da noite.

Digo: 0hs. 32', de 23-XI-55)

o que denota o enorme rigor de Guimarães Rosa, precisando minuciosamente tudo o que faz. Ambos os rascunhos foram encadernados, trazendo - na lombada - o título: Grande sertão: veredas.

Eu estava consciente de que um livro do teor de Grande sertão: veredas, não poderia ter sido escrito sem que previamente muitas idéias tivessem ocorrido ao seu autor. Nada do que ali se encontrava havia sido recolhido inconseqüentemente, tudo tinha seu peso, em tudo se escondia alguma intenção criadora delineada. Assim é que, à procura das razões do texto, de mostrar como a mão tateou antes de tornar definitiva a escritura que hoje conhecemos, me deparei com certos aspectos de conteúdo que, a meu ver, merecem ser revelados, como, por exemplo, este sobre o qual passo agora a discorrer.

No Grande sertão: veredas, o pensar confere a Riobaldo o estatuto de filósofo que Guimarães Rosa aspirava imprimir à imagem do Jagunço. Observem-se essas passagens do romance, propositadamente por mim grifadas:

Eu pensava, como pensava, como o quem-quem remexe no esterco das vacas. Tudo o que me vinha, era só entreter um planejado. (...) Coisa cravada. Nela eu pensava, ansiado ou em brando, como a água das beiras do rio finge que volta para trás, como a baba do boi cai em tantos sete fios. (p. 304)

Conforme eu pensava: tanta coisa já passada; e, que é que eu era? Um raso jagunço atirador, cachorrando por esse sertão. $\mathrm{O}$ mais que eu podia ter sido capaz de pelejar certo, de ser e de fazer; e no real eu não conseguia. (...) Mas, por que? - eu pensava. (p. 305). 
Mas resta muito claro que a angústia existencial de Riobaldo não é como afirma Donaldo Schüller - a angústia específica de um jagunço: "Os conflitos de Riobaldo são os conflitos do homem ocidental na primeira metade do século XX"1. Para Guimarães Rosa, o Jagunço não pensa diferente dos outros homens no que concerne ao seu próprio estar-no-mundo.

Em "O homem dos avessos”, Antonio Candido chama atenção ao fato de que "o jagunço de Guimarães Rosa não é salteador; é um tipo híbrido entre capanga e homem-de-guerra. $\mathrm{O}$ verbo que os personagens empregam para descrever a sua atividade é guerrear, qualificando-se a si mesmos de guerreiros..." ${ }^{2}$, o que mostra o jagunço de um ângulo de visão inteiramente inusitado.

Antonio Candido chama igualmente a atenção às afinidades apontadas por M. Cavalcanti Proença, entre o Grande sertão: veredas e os romances de Cavalaria ${ }^{3}$, acentuando o profundo traço de liberdade que distingue os jagunços, cuja ética particular, corporativa como a dos paladinos medievais, é "liberta em relação à sociedade geral". Mais adiante lembra que o jagunço adere ao grupo, ao bando, "para se ver livre no sertão"

Só assim, livre, poderia ver-se como guerreiro, como agente de uma ação épica, da mesma forma que só um grupo de indivíduos livres e iguais poderia inspirar um autêntico relato épico como é o Grande sertão: veredas. A relação necessária entre liberdade e épica é bem definida por Francesco De Sanctis ao afirmar que para haver uma narrativa épica é necessário "che la società sia libera e che gl'individui siano liberi", exemplificando com o Aquiles homérico: "finché dura la forza fisica, dura la poesia épica e il regno degli eroi"6.

Sendo os romances de Cavalaria um gênero que apresenta analogias com a épica grega de Homero, e reconhecida como é a dependência do Grande sertão em relação aos relatos medievais (Cf. Antonio Candido: "Sobre o fato concreto e verificável da jagunçagem, elabora-se um romance de Cavalaria, e a unidade profunda do livro se realiza quando a ação lendária se

\footnotetext{
${ }^{1}$ Grande sertão: veredas - estudos. In Coutinho, E., Guimarães Rosa, p. 364.

${ }^{2}$ In Coutinho, E. Guimarães Rosa, p. 300.

${ }^{3}$ Cf. Proença, M. Cavalcanti. Trilhas do Grande sertão. In Augusto dos Anjos e outros ensaios.

${ }^{4}$ In Coutinho, E., Guimarães Rosa, p. 301.

${ }^{5}$ Id., p. 308.

${ }^{6}$ Apud Codino, Fausto. Introduzione a Omero, p. 156.
} 
articula com o espaço mágico"7), indaguei-me se não seria possível remontar além da "contaminação dos padrões medievais" até o modelo arquetípico de todos os relatos heróicos, de forma a investigar na Ilíada homérica elementos que remanescem no romance de Guimarães Rosa, "avatar sertanejo da Cavalaria", como o denomina Antonio Candido, no texto tantas vezes aqui citado ${ }^{9}$, esboçando algumas considerações a respeito da correspondência entre esses dois universos épicos, ou seja, entre a saga homérica e a roseana.

Inegável me parece o já apontado traço de absoluta liberdade, presente tantos nos heróis participantes da expedição punitiva contra o raptor Paris em terras troianas, quantos nos guerreiros empenhados em punir o traidor Hermógenes nas terras da Bahia. Por sua vez, da mesma forma que uma estreita amizade liga Riobaldo a Diadorim, Aquiles e Pátroclo vivem em nível idêntico a camaradagem guerreira. $O$ paralelo aqui, porém, embora sedutor, é necessariamente curto, pois a ligação entre os dois guerreiros aqueus é absolutamente destituída de qualquer subentendido: Aquiles e Pátroclo cresceram juntos, mas se no acampamento dormem na mesma barraca, é em pontos opostos, e cada um deles com a prisioneira que lhe agrada. Aquiles enfim ama a escrava Briseida e a cólera que nele se desencadeia quando Agamenon se apossa dela é que vai constituir o motivo mesmo do grandioso poema. É verdade que essa cólera terá perfeito paralelo nos momentos finais da narrativa, quando Pátroclo é morto por Heitor. Aquiles então parecerá um leão enfurecido mas nada disso contraria o status quo permanente durante todo o poema: a amizade viril de um lado, amor heterossexual do outro. Assim o trinômio Aquiles-Pátroclo-Briseida não é perfeitamente simétrico ao trinômio Riobaldo-Diadorim-Deodorina: aqui os dois últimos personagens se confundem e é essa ambigüidade mesmo, impossível de pensar-se no mundo micênico, que constitui um dos eixos do relato de Guimarães Rosa.

O tema do travestismo, todavia, faz parte da legenda de Aquiles: procurando evitar que o filho encontre a morte diante de Tróia, a ninfa Tétis decide esconder o rapaz vestido de roupas femininas, na corte de Licomedes, rei de Squíros, onde ele vive ao lado das princesas. O disfarce, porém,

${ }^{7}$ In Coutinho, E., Guimarães Rosa, p. 301.

${ }^{8}$ Id., Ibid., p. 302.

9 Tal indagação me surgiu ao tempo em que descobri no Arquivo Guimarães Rosa, depositado no IEB/USP, anotações do autor sobre a Ilíada. 
não impede que o instinto guerreiro do jovem, despertado por uma astúcia de Ulisses, o leve ao encontro da glória guerreira e da morte. Note-se a inversão das situações: Diadorim se disfarça em homem para ir à guerra; Aquiles é disfarçado em mulher para que não vá à guerra. Este artifício não produz resultado algum. O outro, o de Grande sertão: veredas, é eficaz no plano prático, mas de conseqüências trágicas no tocante à afetividade de Diadorim e de Riobaldo, implacavelmente sacrificada a um imperativo de dever filial, colocado pela "donzela que vai à guerra" como o cumprimento perfeito de seu destino.

O que parece, porém, aproximar as duas esferas é a feição mítica, o teor lendário da narrativa, capaz de conferir ao romance o caráter arcaico próprio às mitologias. A convivência de Guimarães Rosa com a épica homérica é indiscutível e parece ter atingido razoável aprofundamento, conforme atestam as diversas citações extraídas da edição alemã da Ilíada e transcrita no Arquivo. Creio que ao romancista atraía, sobretudo, o vasto campo da hipologia na epopéia. Assim, duas referências, na Ilíada, a Castor e Orestes - amansadores de cavalos - vão ser transpostas ao Grande sertão.

A pasta E17 10 do Arquivo Guimarães Rosa traz o título DANTE HOMERO LA FONTAINE e, embora nela não encontremos indicação precisa de datas, a edição alemã da Ilíada ${ }^{11}$ - que integra o acervo da biblioteca do autor, também depositada no IEB -, traz o milésimo 1940, com letra de Guimarães Rosa, o que permite localizar as anotações nos anos desse decênio, anteriores, portanto, à fatura do Grande sertão. Este volume apresenta inúmeros grifos e chamadas marginais, das quais grande parte foi transcrita na pasta supracitada, que apresenta trinta e três páginas dedicadas à Ilíad $^{12}$. As citações aparecem entremeadas com frases de Guimarães Rosa, oriundas de sua leitura e estão enumeradas - citações e frases - de 1 a 110 . A partir daí, à altura da p. 9, aparecem mais citações da Ilíada e frases do autor, sem numeração alguma, entretanto. É nas páginas iniciais que vamos encontrar, dentre as citações retiradas da edição alemã, versos que têm ligação com o romance de Guimarães Rosa. Por exemplo:

\footnotetext{
${ }^{10} \mathrm{~A}$ numeração das pastas aqui apresentada corresponde à do momento da pesquisa por mim empreendida no IEB/USP.

${ }^{11}$ HOMER, Ilias, Dieterich'sche, Verlagsbuch, Zu Leipzig, 1938.

${ }^{12}$ As anotações a Homero foram retiradas de duas edições: a alemã - já referida - e outra inglesa, não localizada na biblioteca do autor, no IEB/USP.
} 
66 - "Castor, o amansador de cavalos". (E17, p. 6)

peão

m\% "Orestes, amansador de cavalos" (E17, p.9)

A segunda frase, sem numeração, repetindo praticamente a anterior, menciona personagem diferente: Orestes, ao invés de Castor, trazendo à margem o conhecido sinal gráfico usado pelo autor, $\mathbf{m} \%$, e a palavra peão, manuscrita. Tal sinal significaria - segundo informação de Franklyn de Oliveira em depoimento que me concedeu no Rio de Janeiro, em 1986 - cem por cento meu, uma clara alusão à autoria pessoal. Como cultivava o hábito de compor sintagmas a partir de leituras que fazia, bem como transcrever freqüentemente frases de jornais e revistas, registrar expressões ouvidas, cuja autoria indicava, era imprescindível ao controle de sua memória imprimir marca pessoal ao que considerava genuinamente seu, ainda que inspirado por terceiros. Não nos escapa a noção de que tal marca detém significado muito especial: ela como que transmite à frase assinalada a idéia de que a mesma resultou de intensa elaboração, tendo, assim, atingido - ao cristalizar-se -, forma relativamente desejável. Ora, é inevitável relacionar essas às frases do Grande sertão: "Não sou amansador de cavalos!" (GSV, p. 11) e “Tu sendo peão amansador domador?" (GSV, p. 235). Vejamos o significado dessas frases no romance. Se considerarmos o trecho em que a frase aparece no livro enfim publicado, veremos - na seqüência das versões que antecedem o texto definitivo -, que somente a partir do Segundo Rascunho a frase aparece. Trata-se, inclusive, de frase aparentemente sem sentido para o leitor do livro, pois desvinculada inteiramente do contexto em que surge. Sua razão, todavia, encontra-se à página 245 do Primeiro Rascunho, onde Riobaldo narra a volta das Veredas Mortas, após o pacto:

Porque a cavalhada me viu chegar, e se estrepoliu. Que é que cavalo sabe? Uns deles relinchavam de medo: cavalo sempre relincha exagerado. Como aquele relincho riso fininho, e, como não podiam escapulir para longe, que uns suavam e já escumavam e retremiam, que com as orelhas apontavam. Assim ficaram, mas murchado e obedecendo, quando, com uma raiva tão repentina, eu pulei para o meio deles: - "Barzabu! Quieta cambada!” - que eu gritei. Me obedeceram (...) - Tu sendo pião, Tatarana velho?! - que o Ragásio caçoou! 
Ao surgir agora na página 3 do Segundo Rascunho, o "Não sou amansador de cavalos!" oculta significado especialmente grave: a negação do pacto feito. Dizer que não é amansador de cavalos equivale a dizer que não é pactário. No Segundo Rascunho, à página 327, a frase de Ragásio, modificada para “Tu sendo peão, amansador domador?", amarra definitivamente uma passagem à outra, reforçando a idéia da narração como um todo inconsútil, apesar das idas e vindas da naveta nas mãos do tecedor. O aparecimento dela logo no princípio do Segundo Rascunho é a prova real de que Guimarães Rosa relia constantemente os manuscritos, inserindo intercaladas, semeando simetrias na malha da narrativa, de modo a conferir a certas passagens a possibilidade de exprimir realidades transcendentes à linearidade neutra dos vocábulos. À página 236 do texto definitivo, na exata metade do livro impresso, outra passagem liga-se ao que se disse: Riobaldo, rememorando sua vida, interroga-se a certa altura. "Tudo isso posso vender? Se vendo minha alma, estou vendendo também os outros. Os cavalos relincham sem causa”. Notar que, apesar do anacoluto, uma realidade depende de outra, num processo de associação de idéias: pacto, cavalo, e que somente possuindo-se visão de conjunto do livro, pode-se compreender a unidade secreta de segmentos como esses, aparentemente desconectados ${ }^{13}$.

Sucede que esse trecho do livro (GSV, p. 235-7), de onde retirei a passagem imediatamente acima citada, e no qual de certa forma aparece resumida toda a narração de Riobaldo, aparece no Primeiro Rascunho, à página 175, contendo já a frase "os cavalos relincham sem causa". Não conheço o processo de escritura do Primeiro Rascunho: dispunha apenas de um volume datilografado, com correções manuscritas, resultantes de várias leituras do texto. Teria havido anotações anteriores que, por sua vez, sofreram alterações? Às vezes ocorre-me que não teria sido possível elaborar narrativa tão coesa como a do Primeiro Rascunho, sem rigorosa organização prévia. Como saber, porém, ao certo, se houve páginas manuscritas que, ao serem datilografadas, incluíram na metade um resumo do todo? Ou se, já em meio do livro, Guimarães Rosa antecipou palavras que viriam a reaparecer no desfecho final?

Seja como for, mesmo que o Primeiro Rascunho haja sido escrito na seqüência exata que conhecemos, ou seja, ainda que Guimarães Rosa soubesse já que relacionaria em algum escrito aqueles animais e o pacto

\footnotetext{
${ }^{13} \mathrm{Cf}$. Hazin, Elizabeth. No nada, o infinito. In Lanciani, G. João Guimarães Rosa, p. 144 e sgs.
} 
diabólico, fica muito claro que a palavra amansador ata de modo indissolúvel as duas pontas do texto. No Segundo Rascunho, a frase "Não sou amansador de cavalos!" é relativa ao episódio vivido por Riobaldo ao voltar das Veredas Mortas. E é simetricamente a ela que, ainda no Segundo Rascunho, a interrogativa de Ragásio se modifica, com a inserção do substantivo amansador: “Tu sendo peão, amansador, domador?".

Outra reminiscência homérica pode ser apontada na enumeração dos guerreiros, feita por Riobaldo, ao narrar ao seu interlocutor a véspera dum confronto armado:

Aí o senhor via os companheiros, um por um, prazidos, em beira do café. (...) Zé Bebelo, nosso chefe, indo à frente, e que não sediava folga nem cansaço; o Reinaldo - que era Diadorim; o Alaripe, que era de ferro e de ouro; Marcelino Pampa, segundo em chefe; João Concliz, que com o Sesfredo porfiava; o Quipes, sujeito ligeiro $(. . .)^{14}$.

Essa revista mental dos combatentes imediatamente anterior a um entrechoque, é procedimento comum ao repertório épico, princípio sistemático classificatório. Assim, no Livro II da Ilíada, Homero discrimina minuciosamente as forças prestes a empenhar-se em batalha:

(...) Nestor dá o sinal e os chefes põem em ordem os seus guerreiros (...)

Já se levantam; pelas tendas lume

Acendem logo, a refeição preparam;

Cada Argivo a seu nume ofrenda, roga

Livre-o da morte e bélicos perigos.

Ao pai sumo Agamémnon sacrifica

Pingue touro quinquene: os mais conspícuos,

Nestor em frente e Idomeneu, convida;

Um e outro Ajax, Diomedes; sexto Ulisses,

No siso igual a Jove: per si mesmo

Vem Menelau guerreador, ciente

Dos generosos fraternais cuidados.

Com seus bolos nas mãos, a rês circundam

E ora o chefe de heróis (...)

${ }^{14}$ Cf. Grande sertão: veredas, p. 242-3. 
Como na Ilíada, no Grande sertão: veredas, os rios são muito mais do que acidentes geográficos, realidades inanimadas. No poema homérico, o Scamandro aparece como um deus, filho de Zeus, desempenha um papel no combate de Aquiles contra os troianos. É a cólera que o faz transbordar, é uma força superior que o constrange a conter-se no leito. No Grande sertão: veredas, o São Francisco é "acidente físico e realidade mágica, curso d'água e deus fluvial, eixo do Sertão"15. A imensa distância cronológica parece elidir-se nessa divinização de uma força da natureza, animismo que, abolindo um abismo de milênios, equipara culturas tão opostas numa espécie de solidariedade politeísta, com raízes profundas na mente primitiva. A importância de que se revestem os rios de Guimarães Rosa pode ser vislumbrada em carta que o autor escreve a J.J.Villard, seu tradutor francês, em 28 de dezembro de 1962:

(...) estava agora mesmo pensando na solução que terá de dar, analogamente, ao traduzir o GSV, romance tão fluvial e de tantos rios. Se me permite, darei minha opinião, que é apenas de coração (...) No caso do Rio São Francisco, penso que, sem nenhuma dúvida, o melhor seria traduzi-lo sempre por "fleuve". Vejo, no meu "Petit Larousse", que "fleuve" é: "um grand cours d'eau qui aboutit à la mer". Agora, e no caso do Urucúia - que é quase a própria alma do livro? Traduzir-se-ia bem por "rivière" (que também é uma bela palavra) - ? A meu ver, o melhor seria usar-se sempre, ou quase sempre, "la grande rivière Urucúia”. Que acha? (...) Mas veja: à medida que escrevo, evolui o pensamento. Mesmo para o Urucúia, não seria possível, e melhor, misturar-se o emprego: ora de "fleuve", ora de "grande rivière", ora de "rivière", ora de "rio"? Sei que o francês é uma língua disciplinada em rígida ordem. Mas, tratando-se de um monólogo de homem inculto e ardente espírito barroco, penso que isso seria permitido. No texto tudo o que Riobaldo diz oscila permanentemente, ao sabor dos vai-vens de seu estado de espírito, nada guarda fixidez rigorosa. Assim, por exemplo: a pedra preciosa que ele trouxe de Arassuaí às vezes é dita ser um "topázio", às vezes "turmalina", às vezes "ametista". E em muitas outras coisas aparece essa diversidade ambígua. Isso justificaria a solução de adotarmos aquele ecletismo indiferenciado ${ }^{16}$.

\footnotetext{
${ }^{15}$ Candido, Antonio. O homem dos avessos. In Coutinho, E. Guimarães Rosa, p. 297.

${ }^{16} \mathrm{C} 14$, s.n. de paginação. Arquivo Guimarães Rosa (IEB-USP).
} 
A importância de que se revestem os rios no romance de Guimarães Rosa pode ser vista ainda na mudança de nome do personagem narrador ${ }^{17}$. Quando Ana Maria Machado afirmou, a propósito dos apelidos de riobaldo (Baldo, Tatarana, Urutu branco), que "nenhum nome se fixa nele, pois nunca é o mesmo, está sempre em transformação"18, desconhecia provavelmente quantas modificações sofrera, em efeito, o nome real do personagem, ocultadas pelo texto definitivo. Houve primeiramente alteração apenas na sílaba inicial do nome: Deo modificou-se para Rio. A seguir, o restante foi modificado. Deodôlfo, Riodôlfo, Riobaldo. Assim, o segundo nome tem a ver com o primeiro, e o terceiro com o segundo, nada existindo, porém, em comum entre o terceiro e o primeiro. Tenho para mim que a substituição de Deo por Rio é muito significativa. Deo, primeira escolha de Guimarães Rosa, foi grafado possivelmente para indicar oposição ao Dia que aparece em Diadorim. Essas alusões meramente silábicas, discretos prefixos, teriam a função de pôr em confronto, de início dialeticamente, os opostos, os dois princípios, quase de modo maniqueísta, demarcados ao longo do texto do romance, sob suas formas clássicas: o Bem e o Mal; o Claro e o Escuro; o Ser e o Não-Ser. Tal oposição, todavia, vai resolver-se mais tarde, no final do livro, ao revelar-se que o nome verdadeiro de Diadorim é Deodorina: assim, é no personagem enigmático, carregado de hermafroditismo psicológico, naquele ser que funde em si mesmo o demoníaco e o angélico, que se dá a fusão de "dia" (do diabo) e de "deo" (do divino). À medida que o texto flui, a imagem do rio vai aos poucos adquirindo dimensão mítica. "Nesse plano" - escreve Cavalcanti Proença - "o rio é figura de primeira grandeza. Há mesmo no desenrolar da estória, uma indistinção em que ele e herói se confundem, superpondo-se, ou correndo paralelos"19. A expressão de Riobaldo "Rio meu de amor é o Urucúia" (GSV, p. 58) confirma essa mistura do rio com o personagem, expressa na escolha de seu nome.

Analogamente ao que foi dito sobre o Scamandro e os rios do sertão, “o cavalo Siruiz, fogoso, belo, inteligente, infatigável, lembrando a família mágica dos corcéis encantados, que com as armas encantadas completam o equipamento do cavaleiro e permitem operar prodígios" ${ }^{20}$ é irresistivelmente

\footnotetext{
${ }^{17} \mathrm{Cf}$. Hazin, Elizabeth. Os nomes ocultos de Riobaldo e Diadorim. In Anais do III Encontro de Ecdótica e Crítica Genética.

${ }^{18}$ Recado do Nome, p. 57.

${ }^{19}$ Op. cit., p. 178.

${ }^{20}$ Idem, p. 304.
} 
simétrico ao alazão Xantos de Aquiles que, recebendo miraculosamente o dom momentâneo da palavra, profetiza a morte próxima de seu dono. "Coexistência do real e do fantástico"21, o Grande sertão: veredas relaciona-se assim não só com o clima medieval dos romances de Cavalaria, mas, em suas páginas, a "relação arquetípica com o poema épico"22 pode certamente ser rastreada.

Os tangenciamentos propostos entre o Grande sertão: veredas e a épica homérica poderão ser considerados inconvincentes. A tais objeções ousaria contrapor as palavras de Antonio Candido a propósito da genealogia medieval do romance:

É claro que essas interpretações são arbitrárias; além disso, iluminam apenas um dos muitos lados da obra, visando a contribuir para que o leitor esqueça ao menos provisoriamente os pendores naturalistas a fim de penetrar nessa atmosfera reversível, onde se cortam o mágico e o lógico, o lendário e o real ${ }^{23}$.

Finalizando essas considerações, quero deixar claro que acredito que o conhecimento do processo criador de Guimarães Rosa constitui auxílio de valia na compreensão de obra de tal complexidade literária como é Grande sertão: veredas. Examinar o cabedal de suas leituras e a questão de suas influências literárias - através do exame do arquivo - nos leva a observações interessantes. Assim como se aponta no Ulisses de Joyce transposição especular da Odisséia, tentei levantar pontos tangenciais entre Grande sertão: veredas e a Ilíada, levantamento esse possível apenas a partir do exame do arquivo, onde encontrei diversas anotações sobre o livro de Homero. Creio que este fato aponta, definitivamente, para a importância de estudos dessa natureza. Evidentemente as correspondências paródicas Ulisses - Leopold Bloom; Telêmaco - Stephen Dedalus é simbolicamente perfeita, o que não ocorre entre Riobaldo - Aquiles; Diadorim - Pátroclo. Mas num outro nível, também perseguido por Joyce, pode-se descobrir atrás da camaradagem dos dois jagunços a resolução de irredutíveis dualismos naturais: paternidade e filiação, carne e espírito, dia e noite, masculinidade e feminilidade, céu e terra. Além desses conflitos, desses dilaceramentos, se restaura

\footnotetext{
${ }^{21}$ Idem, p. 298.

${ }^{22}$ Cf. Stegagno-Picchio, Luciana. História da Literatura Brasileira, p. 609.

${ }^{23}$ Candido, Antonio. Op. cit., p. 306.
} 
o sentido da unidade: "No que narrei, o senhor talvez ache mais do que eu, a minha verdade" (GSV, p. 454), epiloga Riobaldo.

Veredas a serem trilhadas, essas intuições certamente poderão encontrar no arquivo subsídios indispensáveis, preciosos. A extensão ou a validade de tais aproximações unicamente o convívio com o arquivo poderá revelar.

Seria interessante, ainda, estender a pesquisa a pormenores biográficos de um romancista em cujos textos se acham indissoluvelmente entrelaçadas vida e criação. Afinal pode ser dito aqui que o seu arquivo é estruturado como universo em miniatura por inexistir em Guimarães Rosa distinção entre literatura e vida, postura por ele assumida e, sempre que possível, anunciada: "A literatura tem de ser vida. O escritor deve ser o que ele escreve" 24 , ou "Quando saio montado num cavalo pela minha Minas Gerais, vou tomando nota das coisas. O caderno fica impregnado de sangue de boi, suor de cavalo, folha machucada" 25 , ou ainda: "Todos os meus livros são simples tentativas de rodear e devassar um pouquinho o mistério cósmico, essa coisa movente, impossível, perturbante, rebelde a qualquer lógica, que é a chamada 'realidade', que é a gente mesmo, o mundo, a vida" ${ }^{26}$.

A 27 de outubro de 1953, em carta ao pai Florduardo, afirma:

Há uma semana, escrevi ao senhor uma carta, e hoje tive a alegria de receber a sua, acompanhada das 'notas', que muito agradeço. Todas são ótimas, principalmente a sobre os 'ciganos' e a do 'Entrudo' em Caeté. Vão ser muito bem aproveitadas! Sempre que o Senhor tiver disposição, pode mandar.

$\mathrm{Na}$ carta, falei no interesse que tenho pelo assunto das caçadas da Serra do Cabral - principalmente quanto aos detalhes pitorescos. O detalhe é muitas vezes de grande proveito, pois metido num texto dá impressão de 'realidade ${ }^{27}$.

De Franklyn de Oliveira, durante a visita que lhe fiz no Rio de Janeiro, em princípios de 1986, ouvi depoimento relativo à preocupação de Guimarães Rosa em criar um tipo de literatura que transpirasse realidade. Segundo ele,

\footnotetext{
${ }^{24}$ Lorenz, G. João Guimarães Rosa. In Diálogo com a América Latina, p. 341.

${ }^{25}$ Apud Bloch, Pedro. In Rónai, Paulo (org.), Rosiana, p. 92.

${ }^{26}$ Carta de 9 de fevereiro de 1965, a Meyer-Clason. In Rosa, J. G. Correspondência com seu tradutor alemão, p. 238.

${ }^{27}$ Documento 84/23 do Arquivo Museu de Literatura da Fundação Casa de Rui Barbosa, Rio de Janeiro.
} 
o romancista realmente aspirava a registrar a beleza do flagrante, a coisa viva mesmo. Como o teorema que buscava demonstrar era a equivalência entre verdade e beleza, o arquivo por ele organizado constitui uma ponte ideal entre a realidade e a obra, entre o dado bruto e sua metamorfose verbal, entre o vivido (ou lido) e o escrito.

\section{Referências Bibliográficas}

CANDIDO, Antonio. O homem dos avessos. In COUTINHO, E. (org.) Guimarães Rosa. Rio/Brasília: Civilização Brasileira/INL, 1983, p. 294-309.

CODINO, Fausto. Introduzione a Omero. Torino: Einaldi, 1965.

HAZIN, E. Os nomes ocultos de Riobaldo e Diadorim. In Anais do III Encontro de Ecdótica e Crítica Genética, João Pessoa: UFPB, 1993, p. 329-336. . No nada, o infinito (da gênese do Grande sertão: veredas). In LANCIANI, Giulia (org.) João Guimarães Rosa. Roma: Bulzoni Editore, 2000, p. 135-175.

LORENZ, Günther. João Guimarães Rosa. In Diálogos com a América Latina. São Paulo: E.P.U., 1973, p. 315-355.

MACHADO, Ana Maria. Recado do nome. Rio: Imago, 1976.

PICCHIO, L. Stegagno. História da Literatura Brasileira. Rio: Aguilar, 1997.

PROENÇA, M. Cavalcanti. Trilhas do Grande sertão. In Augusto dos Anjos e outros ensaios. Rio: J. Olympio, 1959, p. 151-241.

RÓNAI, Paulo (org.). Rosiana. Rio: Salamandra, 1983.

ROSA, J. Guimarães. Grande sertão: veredas. 10a . ed. Rio: J. Olympio, 1976.

Meyer-Clason. Rio/Belo Horizonte: Nova Fronteira/ Ed. Da UFMG, 2003.

SCHULLER, Donaldo. Grande sertão: veredas - Estudos. In COUTINHO, E. (org.) Guimarães Rosa. Rio/Brasília: Civilização Brasileira/INL, 1983, p. 360-377.

Recebido em 26 de novembro de 2007

Aceito em 27 de fevereiro de 2008 
